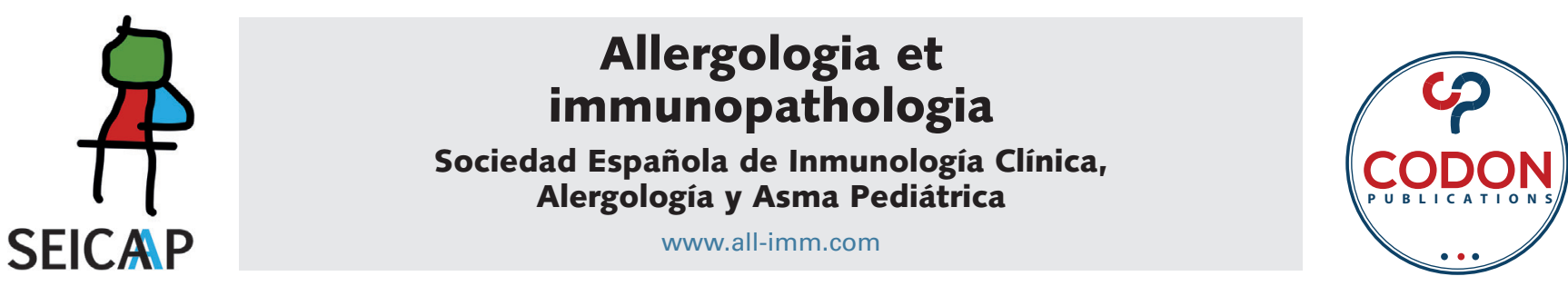

\title{
The relationship between allergic diseases and internalising and externalising behaviours in Spanish children: A cross-sectional study
}

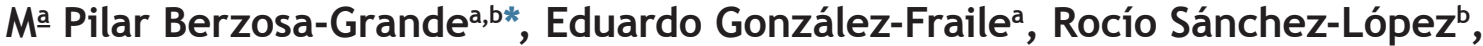 \\ María Soria-Olivera, Santiago Rueda-Estebanc
}

${ }^{a}$ Department of Health Sciences, International University of La Rioja, UNIR, Logroño, Spain

bIntelecto Psychological Centre, Jerez de la Frontera, Spain

'San Carlos Clinic Hospital, Madrid, Spain

Received 15 August 2020; Accepted 22 November 2020

Available online 1 May 2021

\section{KEYWORDS \\ allergy; \\ behaviour; \\ child; \\ internalising and \\ externalising; \\ parent}

\begin{abstract}
Introduction and objectives: The relationship between allergic diseases and behavioural disorders is still unclear. The objective of this study was to describe and compare children's behaviour (internalising and externalising) across a sample of children aged 6-11 years with and without allergic diseases. Materials and methods: This was a cross-sectional observational case-control study. A survey to 366 families (194 allergic cases and 172 controls), including a child behaviour checklist $(\mathrm{CBCL})$ and a socio-demographic questionnaire with questions related to family, school education, health conditions and allergy symptoms, was administered. Results: Children with a diagnosis of allergy showed higher scores in the overall $\mathrm{CBCL}$ score (standardised mean differences $[S M D]=0.47$; confidence intervals $[\mathrm{Cl}]: 0.26-0.68$ ) and in the internalising and externalising factors $(S M D=0.52$ and $S M D=0.36$, respectively) than non-allergic children. Odds ratio $(\mathrm{OR})$ analyses showed a higher risk $(\mathrm{OR}=2.76 ; 95 \% \mathrm{Cl}[1.61$ to 4.72]) of developing a behavioural difficulty in children diagnosed with allergies. Age and level of asthma appear as modulatory variables. Conclusions: Children aged 6-11 years diagnosed with allergies showed larger behavioural problems than non-allergic children, especially in the case of internalising behaviours. These findings suggest the importance of attending to them and treating them in the early stages of diagnosis to avoid future psychological disorders.

(c) 2021 Codon Publications. Published by Codon Publications.
\end{abstract}

*Corresponding author: Ma Pilar Berzosa-Grande, International University of La Rioja, C/Gran Vía Rey Juan Carlos I, 41, 26002 Logroño, La Rioja, Spain. Email address: mariapilar.berzosa@unir.net 


\section{Introduction}

The prevalence of allergic diseases has increased globally for more than 50 years, especially in industrialised countries $^{1}$ and in children aged less than 18 years. ${ }^{2-4}$ This rise in the prevalence of allergies has a great impact on societies as it generates high healthcare costs.,6 Families and children with allergic diseases are particularly affected and bear the maximum burden, ${ }^{7}$ which is reflected in reduction of their quality of life, ${ }^{8}$ an increased risk of psychological disorders ${ }^{9}$ and numerous medical and non-medical comorbidities. ${ }^{10}$

Over the past few decades, evidence about the relationship between common allergies (related to environmental factors, foods and drugs), their main symptoms (such as asthma, allergic rhinitis [AR] or atopic dermatitis [AD]) and mental health problems in children and young adults has become stronger. ${ }^{11-14}$ Asthma is related with a higher risk of internalising disorders (such as anxiety and depression), ${ }^{15}$ externalising disorders (such as oppositional defiant or disruptive behaviour disorders) ${ }^{16,17}$ or poorer social and mental well-being. ${ }^{18}$ Different studies on allergic rhinitis in children and pre-schoolers have shown a relationship between internalising and sleep problem behaviours. ${ }^{19-22}$ In addition, atopic dermatitis has been associated in different studies with several mental comorbidities such as attention deficit disorder, anxiety and depression. ${ }^{23}$ However, a recent meta-analysis of 35 studies on atopic dermatitis has found opposite results. ${ }^{24}$

On the other hand, the relation between allergic diseases and these internalising/externalising difficulties is not clear. Some psychological approaches have suggested that children could have psychological adjustment difficulties because of an allergy and its symptoms, ${ }^{25}$ or that these could be influenced by intra-familial or socio-emotional factors related to family circumstances. ${ }^{26-29}$ Others have explored the relationship with an underlying biological process related to the serotoninergic system..$^{30,31}$

In spite of these evidences, there is a lack of studies assessing outcomes with well-validated instruments that compare a clinical allergic sample with a similar control sample of non-allergic children. In addition, no study has assessed the possible relationship between multiple comorbid allergies and behavioural problems. ${ }^{19}$

The aim of this study was to assess relationship between allergic diseases and behavioural problems (internalising and externalising). The possible influence of intra-familial conditions (such as level of stress in the family, affective expressions, resilience and parental authority) into the origin of behavioural problems in allergic children was also studied. In addition, we aimed to assess the relationship between the severity of allergy (mild or moderate asthma and the number of allergic comorbidities) and the degree of behavioural problems.

\section{Methods}

\section{Hypothesis and design}

The principal hypothesis of this study was that children (aged 6 to 11 years) with a diagnosis of an allergic disease would show higher behavioural problems (internalising and externalising problems), assessed using the child behaviour checklist $(\mathrm{CBCL}){ }^{32}$ than the children without a diagnosis of allergic disease.

The secondary hypothesis was that children (aged 6 to 11 years) with a diagnosis of an allergic disease would show higher scores on eight syndrome subscales of the CBCL scale s2 $^{32}$ (anxious/depressed, withdrawn/depressed, somatic complaints, social problems, thought problems, attention problems, rule-breaking behaviour and aggressive behaviour) than children without a diagnosis of allergic disease.

Third hypothesis was that there is a positive relation between the severity of the allergy (assessed by the degree of asthma and the number of allergic comorbidities) and the level of behavioural problems.

This study design was carried out as a multicentre, case-control, cross-sectional study.

\section{Sample}

The study population included two groups. The first group (cases/patients) comprised families with a child diagnosed with an allergic disease. To be eligible to be included in this group, families had to fulfil the following criteria: (i) they must have a male or female child (aged 6 to 11 years), (ii) being treated in an external paediatric pneumology/allergology service, (iii) for a clinically diagnosed mild or moderate environmental allergy (including pollen, mould, dust or pets), food allergy, medication allergy, allergic asthma, allergic rhinitis or atopic dermatitis, and (iv) allergy symptomatology must be stable and well controlled by a clinician. Exclusion criteria included: (i) children with a severe clinical diagnosis of allergy, (ii) comorbidity of another primary pathology, (iii) having a direct family member (parents or siblings) with severe mental disorder (Diagnostic and Statistical Manual of Mental Disorders, 5th version [DSM-V] criteria), and (iv) being hospitalised. The sample for this group was recruited from the Clinical Hospital of San Carlos, located in Madrid (Spain). A clinician individually informed families about the study and its purposes and asked them about their interest to participate in the study.

The second group (controls) comprised families with healthy children. To be included in this group, families must fulfil the following criteria: (i) they must have a male or female child (aged 6 to 11 years). Exclusion criteria for this group included having a child: (i) with a clinical diagnosis of allergy, (ii) comorbidity of another primary pathology, (iii) direct family (parents or siblings) with a severe mental disorder (DSM-V criteria), and (iv) being hospitalised. The full sample for this group was recruited from a state-financed school in Madrid (Spain). In this case, the team met the families of the children to inform them about the study and its purposes. Forms (informed consent and survey forms) were sent by post at their homes. Families interested to participate in the study forwarded the documentation with the requested information.

Parents of both groups signed the written informed consent before included in the study. Study approval was obtained from the Ethical and Scientific Research Committee of the San Carlos Clinic Hospital, Madrid (Spain) in April 2019 (internal code: 19/108-E). 


\section{Assessment}

\section{Socio-demographic and emotional climate in the family}

To collect socio-demographic information, the team developed an ad hoc questionnaire with questions related to age, sex, number of brothers and sisters of the child and family structure (nuclear, separated, adoptive etc.).

To detect emotional circumstances of the family, a brief ad hoc questionnaire was used. In this questionnaire, parents used a 3-point Likert scale (low, medium or high) to rate their perceived levels of stress in the family, affective expressions, resilience to cope with familial problems and difficulties, and their authority or effectiveness in establishing rules in the family (see Supplementary material: 'Data of Your Child's Family Context').

\section{Allergy information}

Information about the allergy of the participants of allergic group was collected directly by a clinician from medical files. It includes information concerning allergen (pollen, mould, dust, pets, food or medication), level of asthma (mild or moderate), atopic dermatitis, allergic rhinitis and food intolerance. Participants in the control group were also asked all these questions in order to ensure that they did not suffer from any allergy or show symptoms of allergy.

\section{Behavioural outcome measure}

To assess behavioural problems, parents completed the child behaviour checklist (CBCL). ${ }^{32}$ The CBCL can be applied to subjects aged 4-16 years. It includes 113 statements recorded on a 4-point ( 0 - 3 ) Likert scale $(0=$ 'false or rarely'; 3 ='true or very often'). The items are grouped into nine independent factors: anxious/depressed, withdrawn/ depressed, somatic complaints, social problems, attention problems, rule-breaking behaviour, aggressive behaviour and other problems. The scale gives three summary scores related to internalising behaviour problems (formed by the sum of the factors of anxious/depressed, withdrawn/ depressed and somatic complaints), externalising behaviour problems (sum of rule-breaking behaviour and aggressive behaviour) and a total score (obtained by the addition of all the factors). To interpret these scores, direct scores were converted to a T scale where scores between 65 and 70 were considered as critical borderline clinical range. Higher scores meant higher levels of behavioural problems. We used the Spanish version of the CBCL for children aged 6-18 years. $^{33}$

Parents completed the parent rating scale of the $\mathrm{CBCL}$ and the ad hoc questionnaires.

\section{Sample size calculation}

Taking into account that the $10 \%$ of general child population can show any disruptive behaviour, ${ }^{34}$ and accepting an alpha risk of 0.05 and a beta risk of 0.2 in a two-sided test, 195 subjects were necessary in both groups in order to find a statistically significant difference in proportions, expected to be 0.1 in allergic group and 0.2 in the control group.

\section{Statistical analysis}

Sample description was reported by mean values and standard deviations (SDs) for continuous variables, whereas frequencies and percentages described categorical variables.

To contrast the main hypothesis of the study we used simple means of comparisons (Student's t-test or the MannWhitney $U$ test). In addition, simple mean differences and standardised mean differences (SMD) with 95\% confidence intervals $(95 \% \mathrm{Cl})$ and odds ratios (ORs) were determined. SMD could be easily interpreted following the rule of thumb: scores from 0 to 0.2 indicated a small effect, values near to 0.5 suggested medium effect, and 0.8 or above values could be interpreted as a large effect. ${ }^{35}$ To calculate OR we separated the obtained CBCL scores using a T score of 65 as the cut-off point, marked by the original authors of the scale as 'clinical range'. An OR value of more than 1 was interpreted as higher odds of the described event occurring, given the particular exposure. In case of any statistically significant differences in socio-demographic or familial variables between groups, secondary analysis was performed by logistic regression, adjusting for covariates.

Association between the severity of allergy (assessed by the degree of asthma and the number of allergic comorbidities) and the level of behavioural problems was examined using a Student's t-test (degree of asthma has only two categories) and a Pearson correlation (one participant could have from one to four allergies). For these dose-relation analyses, we used the allergic group.

An independent and blinded statistician performed analyses using SPSS V.21 (IBM SPSS Statistics for MAC, version 24.0, IBM Corp., Armonk, NY) and Jamovi 1.2 (Jamovi project, Jamovi, version 1.2).

\section{Results}

\section{Sample description}

A total of 456 families were assessed for eligibility; twenty-three $(5.04 \%)$ did not meet the selection criteria and 67 refused to participate (14.69\%). Finally, we recruited a total of 366 families (80.26\%) (194 patients and 172 controls) from May to July 2019. Table 1 presents characteristics of the main sample obtained from the questionnaires distributed in groups.

The total sample had a mean age of 8.68 years, while the allergic group showed a higher mean age than the control group. Overall, allergic group reported allergies to environmental elements (pollen, mould, dust or pets); 38 children indicated food allergies and only five showed allergy to pharmacological compounds. All patients in the allergic group were diagnosed with asthma, and 123 children had atopic dermatitis. The most frequent family structure was traditional or nuclear followed by separated or divorced. Assessment of emotional circumstances from the context of family indicated that the level of stress was 
Table1 Sociodemographic description of the sample.

\begin{tabular}{|c|c|c|c|c|}
\hline Variables & Total $(\mathrm{N}=366)$ & Allergic $(n=194)$ & Control $(n=172)$ & P-value \\
\hline Age, mean (SD) & $8.68(1.71)$ & $9.01(1.62)$ & $8.31(1.72)$ & $<0.001$ \\
\hline Female gender, n (\%) & $173(47.3)$ & $85(43.8)$ & $88(51.2)$ & 0.160 \\
\hline \multicolumn{5}{|l|}{ Allergy, n (\%) } \\
\hline Pollen & - & $163(84.02)$ & - & \\
\hline Mould & - & 27 (13.91) & - & \\
\hline Dust & - & $24(12.37)$ & - & \\
\hline Pets & - & $63(32.47)$ & - & \\
\hline Food & - & $38(19.58)$ & - & \\
\hline Medication & - & $5(2.57)$ & - & \\
\hline \multicolumn{5}{|l|}{ Level of asthma, n (\%) } \\
\hline Mild & - & $151(77.83)$ & - & \\
\hline Moderate & - & $43(22.16)$ & - & \\
\hline Severe & - & 0 & - & \\
\hline Atopic dermatitis, n (\%) & $123(63.4)$ & $123(63.4)$ & 0 & $<0.001$ \\
\hline Rhinitis, n (\%) & $171(88.14)$ & $171(88.14)$ & 0 & $<0.001$ \\
\hline Alimentary intolerance, n (\%) & $12(3.27)$ & $12(6.18)$ & 0 & $<0.001$ \\
\hline \multicolumn{5}{|l|}{ Family structure, n (\%) } \\
\hline Nuclear & $251(68.6)$ & $130(67)$ & $122(70.9)$ & 0.091 \\
\hline Separated or divorced & $54(14.7)$ & $28(14.4)$ & $26(15.1)$ & \\
\hline Stepfamily & $26(7.1)$ & $16(8.2)$ & $10(5.8)$ & \\
\hline Adoptive & $5(1.4)$ & $1(0.5)$ & $4(2.3)$ & \\
\hline Single parent & $20(5.5)$ & $15(7.7)$ & $5(2.9)$ & \\
\hline Others & $10(2.7)$ & $4(2.1)$ & $5(2.9)$ & \\
\hline \multicolumn{5}{|l|}{ Family-perceived stress } \\
\hline Low & $220(60.2)$ & $111(57.2)$ & $109(63.4)$ & 0.668 \\
\hline Medium & $123(33.6)$ & $71(36.6)$ & $52(30.2)$ & \\
\hline High & $23(6.2)$ & $12(6.2)$ & $11(6.4)$ & \\
\hline \multicolumn{5}{|l|}{ Parents' affective expression } \\
\hline Low & $19(5.2)$ & $11(5.7)$ & $8(4.7)$ & 0.804 \\
\hline Medium & $25(6.8)$ & $12(6.2)$ & $13(7.6)$ & \\
\hline High & $322(88)$ & $171(88.1)$ & $151(87.8)$ & \\
\hline \multicolumn{5}{|l|}{ Parents resilience } \\
\hline Low & $64(17.5)$ & $31(16)$ & 33 (19.2) & 0.187 \\
\hline Medium & 187 (51.1) & $94(48.5)$ & $93(54.1)$ & \\
\hline High & 115 (31.4) & $69(35.6)$ & $46(26.7)$ & \\
\hline \multicolumn{5}{|l|}{ Authority's effectiveness } \\
\hline Low & 37 (9.9) & $18(9.3)$ & 19 (10.5) & 0.508 \\
\hline Medium & $189(51.8)$ & $106(54.6)$ & 83 (48.5) & \\
\hline High & $140(38.5)$ & $70(36.1)$ & 70 (40.9) & \\
\hline
\end{tabular}

predominately low, with a high degree of affective expressions and medium degree of resilience and authority.

No significant differences were observed between allergic and control groups in relation to intra-familial conditions.

\section{Comparisons of behaviour (CBCL) by group (allergic and control groups)}

Table 2 shows scores on the CBCL scale. The overall sample obtained a mean total score of 26.71 , indicating non-clinical behaviour. Allergic children showed higher scores, with a significant mean difference of 10.27 points above the control group $(\mathrm{SMD}=0.47 ; 95 \% \mathrm{Cl}[0.26$ to 0.68$])$. Internalising and externalising subscales reported similar differences between groups with medium effect sizes $(S M D=0.52$;
$95 \% \mathrm{Cl}[0.32$ to 0.73 ] and $\mathrm{SMD}=0.36 ; 95 \% \mathrm{Cl}[0.15$ to 0.56 , respectively).

The remaining factors, except 'rule-breaking behaviour', showed similar statistical results $(P>0.025)$ with medium effect sizes. The largest differences were detected in the subscales of 'somatic complaints' $(S M D=0.57)$ and 'thought problems' ( $S M D=0.43)$, while the smallest differences were in the subscale of 'attention problems' $(S M D=0.29)$ and 'others' (SMD=0.26).

Logistic regressions adjusted for covariates (age and number of siblings) reported similar results $(P<0.01$ for the total score, internalising and externalising subscales; and $\mathrm{P}<0.05$ for the remaining factors except for the 'rule-breaking behaviour' subscale). A comparison between the younger (aged 6-8 years) and the older participants (aged 9-11 years) showed smaller differences (SMD) in all scores, especially for externalising sub-domain (Table 3). 
Table 2 Comparisons of child behaviour checklist (CBCL) scores by groups.

\begin{tabular}{|c|c|c|c|c|c|c|c|}
\hline & $\begin{array}{c}\text { Total } \\
(\mathrm{N}=366)\end{array}$ & $\begin{array}{l}\text { Allergic } \\
(n=194)\end{array}$ & $\begin{array}{l}\text { Control } \\
(n=172)\end{array}$ & P-value & $\begin{array}{c}\text { Mean } \\
\text { difference }\end{array}$ & $\begin{array}{c}\text { SMD } \\
(95 \% \mathrm{Cl})\end{array}$ & $\begin{array}{c}\text { OR } \\
(95 \% \mathrm{Cl})\end{array}$ \\
\hline $\begin{array}{l}\text { CBCL total, mean } \\
\text { (SD) }\end{array}$ & $26.71(21.32)$ & $31.28(22.45)$ & $21.55(18.74)$ & $<0.001$ & -10.27 & $\begin{array}{r}0.47[0.26 \\
\text { to } 0.68]\end{array}$ & $\begin{array}{r}2.76[1.61 \\
\text { to } 4.72]\end{array}$ \\
\hline Anxious/depressed & $3.39(3.52)$ & $4.06(3.88)$ & $2.63(2.9)$ & $<0.001$ & -1.55 & $\begin{array}{r}0.41[0.21 \\
\text { to } 0.62]\end{array}$ & $\begin{array}{r}2.83[1.41 \\
\text { to } 5.66]\end{array}$ \\
\hline $\begin{array}{l}\text { Withdrawn/ } \\
\text { depressed }\end{array}$ & $1.63(2.32)$ & $2(2.65)$ & $1.21(1.8)$ & $<0.001$ & -0.88 & $\begin{array}{r}0.34[0.14 \\
\text { to } 0.55]\end{array}$ & $\begin{array}{l}1.5[0.84 \\
\text { to } 2.67]\end{array}$ \\
\hline Somatic complaints & $2.33(2.7)$ & $3.03(2.98)$ & $1.54(2.07)$ & $<0.001$ & -1.49 & $\begin{array}{r}0.57[0.36 \\
\text { to } 0.78]\end{array}$ & $\begin{array}{c}1.51 \text { [ } 1.38 \\
\text { to } 4.53]\end{array}$ \\
\hline Social problems & $2.45(2.7)$ & $2.93(2.89)$ & $1.91(2.35)$ & $<0.001$ & -1.08 & $\begin{array}{r}0.38[0.18 \\
\text { to } 0.59]\end{array}$ & $\begin{array}{r}3.31[1.52 \\
\text { to } 7.19]\end{array}$ \\
\hline Thought problems & $2.07(2.53)$ & $2.57(2.71)$ & $1.5(2.18)$ & $<0.001$ & -1.18 & $\begin{array}{r}0.43[0.22 \\
\text { to } 0.64]\end{array}$ & $\begin{array}{l}2.41[1.19 \\
\text { to } 4.89]\end{array}$ \\
\hline Attention problems & $4.18(3.71)$ & $4.69(3.78)$ & $3.61(3.55)$ & 0.002 & -1.18 & $\begin{array}{c}0.29[0.09 \\
\text { to } 0.5]\end{array}$ & $\begin{array}{r}1.44[0.71 \\
\text { to } 2.91]\end{array}$ \\
\hline $\begin{array}{l}\text { Rule-breaking } \\
\text { behaviour }\end{array}$ & $1.63(1.96)$ & $1.74(2.11)$ & $1.5(1.76)$ & 0.221 & -0.25 & $\begin{array}{c}0.12[-0.08 \\
\text { to } 0.33]\end{array}$ & $\begin{array}{r}1.89[0.72 \\
\text { to } 4.91]\end{array}$ \\
\hline Aggresive behaviour & $5.02(4.61)$ & $5.92(4.81)$ & $4(4.16)$ & $<0.001$ & -1.93 & $\begin{array}{r}0.42[0.22 \\
\text { to } 0.63]\end{array}$ & $\begin{array}{l}2.5[1.17 \\
\text { to } 5.36]\end{array}$ \\
\hline Others & $3.97(2.96)$ & $4.29(3.02)$ & $3.61(2.86)$ & 0.025 & -0.69 & $\begin{array}{r}0.26[0.06 \\
\text { to } 0.47]\end{array}$ & - \\
\hline Internalizing & $7.36(7.29)$ & $9.10(8.14)$ & 5.39 (5.59) & $<0.001$ & -3.93 & $\begin{array}{r}0.52[0.32 \\
\text { to } 0.73]\end{array}$ & $\begin{array}{r}2.45[1.54 \\
\text { to } 3.89]\end{array}$ \\
\hline Externalizing & $6.65(6.14)$ & $7.67(6.41)$ & $5.50(5.62)$ & $<0.001$ & -2.18 & $\begin{array}{r}0.36[0.15 \\
\text { to } 0.56]\end{array}$ & $\begin{array}{r}1.77[1.03 \\
\text { to } 3.04]\end{array}$ \\
\hline
\end{tabular}

CBCL: child behaviour checklist; $\mathrm{Cl}$ : confidence interval; SD: standard deviation; SMD: standardized mean difference; OR: odds ratio.

Table 3 Comparisons of child behaviour checklist (CBCL) scores by groups and age (under and over 9 years old).

\begin{tabular}{|c|c|c|c|c|c|c|c|c|}
\hline & \multicolumn{4}{|c|}{ Under 9 years } & \multicolumn{4}{|c|}{ Over 9 years } \\
\hline & $\begin{array}{l}\text { Allergic } \\
(n=78)\end{array}$ & $\begin{array}{l}\text { Control } \\
(n=95)\end{array}$ & P-value & $\begin{array}{c}\text { SMD } \\
(95 \% \mathrm{Cl})\end{array}$ & $\begin{array}{l}\text { Allergic } \\
(n=116)\end{array}$ & $\begin{array}{l}\text { Control } \\
(n=77)\end{array}$ & $\mathrm{P}$-value & $\begin{array}{c}\text { SMD } \\
(95 \% \mathrm{Cl})\end{array}$ \\
\hline $\begin{array}{l}\text { CBCL total, } \\
\text { mean (SD) }\end{array}$ & 30.69 (21.53) & $19.08(16.06)$ & $<0.001$ & $\begin{array}{r}0.62[5.96 \\
\text { to } 17.25]\end{array}$ & $31.68(23.14)$ & $24.61(21.31)$ & 0.033 & $\begin{array}{l}0.31[0.56 \\
\text { to } 13.57]\end{array}$ \\
\hline $\begin{array}{l}\text { Anxious/ } \\
\text { depressed }\end{array}$ & $4.01(3.88)$ & $2.28(2.63)$ & $<0.001$ & $\begin{array}{r}0.53[0.74 \\
\text { to } 2.71]\end{array}$ & $4.10(3.90)$ & 3.08 (3.17) & 0.056 & $\begin{array}{c}0.28[-0.02 \\
\text { to } 2.07]\end{array}$ \\
\hline $\begin{array}{l}\text { Withdrawn/ } \\
\text { depressed }\end{array}$ & 1.62 (1.96) & $1.12(1.81)$ & 0.084 & $\begin{array}{c}0.26[-0.06 \\
\text { to } 1.06]\end{array}$ & 2.27 (3.01) & $1.34(1.80)$ & 0.016 & $\begin{array}{r}0.35[0.17 \\
\text { to } 1.62]\end{array}$ \\
\hline $\begin{array}{l}\text { Somatic } \\
\text { complaints }\end{array}$ & 3.05 (3.37) & $1.38(1.83)$ & $<0.001$ & $\begin{array}{r}0.63[0.87 \\
\text { to } 2.46]\end{array}$ & $3.02(2.71)$ & $1.74(2.34)$ & $<0.001$ & $\begin{array}{r}0.49[0.53 \\
\text { to } 2.02]\end{array}$ \\
\hline $\begin{array}{l}\text { Social } \\
\text { problems }\end{array}$ & $2.74(2.66)$ & 1.72 (1.95) & 0.004 & $\begin{array}{r}0.44[0.52 \\
\text { to } 2.67]\end{array}$ & $3.06(3.05)$ & $2.17(2.77)$ & 0.041 & $\begin{array}{r}0.30[0.03 \\
\text { to } 1.74]\end{array}$ \\
\hline $\begin{array}{l}\text { Thought } \\
\text { problems }\end{array}$ & $2.6282 .63)$ & $1.39(2.13)$ & $<0.001$ & $\begin{array}{l}0.51[0.5 \\
\quad \text { to } 1.94]\end{array}$ & $2.55(2.79)$ & $1.65(2.26)$ & 0.019 & $\begin{array}{r}0.34[0.15 \\
\text { to } 1.65]\end{array}$ \\
\hline $\begin{array}{l}\text { Attention } \\
\text { roblems }\end{array}$ & $4.81(3.86)$ & $3.21(3.30)$ & 0.004 & $\begin{array}{r}0.44[0.52 \\
\text { to } 2.67]\end{array}$ & 4.62 (3.75) & $4.12(3.80)$ & 0.364 & $\begin{array}{c}0.13[-0.58 \\
\quad \text { to } 1.59]\end{array}$ \\
\hline $\begin{array}{c}\text { Rule-breaking } \\
\text { behaviour }\end{array}$ & $1.58(1.83)$ & 1.27 (1.61) & 0.248 & $\begin{array}{c}0.17[-0.21 \\
\text { to } 0.82]\end{array}$ & $1.86(2.28)$ & $1.78(1.92)$ & 0.793 & $\begin{array}{c}0.03[-0.53 \\
\text { to } 0.70]\end{array}$ \\
\hline $\begin{array}{l}\text { Aggresive } \\
\text { behaviour }\end{array}$ & $5.97(4.37)$ & $3.36(3.38)$ & $<0.001$ & $\begin{array}{r}0.67[1.45 \\
\text { to } 3.78]\end{array}$ & $5.90(5.10)$ & $4.81(4.88)$ & 0.140 & $\begin{array}{c}0.21[-0.36 \\
\text { to } 2.54]\end{array}$ \\
\hline Others & 4.29 (3.35) & $3.36(2.60)$ & 0.040 & $\begin{array}{r}0.31[0.04 \\
\text { to } 1.83]\end{array}$ & $4.30(2.79)$ & 3.94 (83.15) & 0.397 & $\begin{array}{c}0.12[-0.48 \\
\quad \text { to } 1.21]\end{array}$ \\
\hline Internalizing & 8.68 (8.31) & $4.78(5.05)$ & $<0.001$ & $\begin{array}{r}0.58[1.87 \\
\text { to } 5.92]\end{array}$ & 9.39 (8.06) & $6.16(6.15)$ & 0.003 & $\begin{array}{r}0.43[1.09 \\
\text { to } 5.36]\end{array}$ \\
\hline Externalizing & 7.55 (5.66) & $4.63(4.62)$ & $<0.001$ & $\begin{array}{r}0.62[5.96 \\
\text { to } 17.25]\end{array}$ & 7.76 (6.91) & $6.58(6.53)$ & 0.239 & $\begin{array}{l}0.17[-0.78 \\
\quad \text { to } 3.13]\end{array}$ \\
\hline
\end{tabular}




\section{Odds Ratios}

According to the results, children with allergies are 2.76 times more likely to have behavioural problems than children without allergies ( $\mathrm{P} \leq 0.001 ; 95 \% \mathrm{Cl}$ [1.61 to 4.72]). The OR for externalising and internalising subscales showed significantly similar results $(\mathrm{P}=0.03$ and 0.001 , respectively), indicating the same relationship. The OR was higher in internalising factor than in externalising factor $(2.45$ against 1.77). The factor of 'social problems' obtained the highest $\mathrm{OR}$ in the overall scale $(\mathrm{OR}=3.31 ; 95 \% \mathrm{Cl}[1.52$ to 7.19$])$ followed by the 'anxious/depressed' factor (OR=2.83; 95\% $\mathrm{Cl}$ [1.41 to 5.66]). Factors such as 'withdrawn/depressed', 'attention problems' and 'rule-breaking behaviour' showed the smallest and non-statistically significant OR $(95 \% \mathrm{Cl}$ included value of 1 ).

\section{Allergy severity}

Comparisons between children with mild or moderate level of asthma showed higher and significant scores in the subsample of moderate asthma (see Table 4) in the total score and in the internalising sub-domain.

Correlations between the number of allergies and $\mathrm{CBCL}$ scores did not show relevant results $(P<0.05)$.

\section{Discussion}

The prevalence of allergies in children has grown in last few decades. ${ }^{36}$ Allergies are very often associated with physical, mental and emotional problems that could be detected through child's behaviour and feelings. ${ }^{22}$

The results of this study confirm the main hypothesis that children with allergic diseases show a higher risk of suffering with behavioural problems (internalising and externalising) than healthy subjects. Both types of factors show differences, with those in internalising factor appear to be greater. These results are similar to that of other studies. ${ }^{19,37}$

The secondary hypothesis also appears to be confirmed. Children with allergies showed higher scores in all the subscales with the exception of 'rule-breaking behaviour'.

The fact that the subscale of 'rule-breaking behaviour' did not show significant differences and the absence of differences in the emotional climate of the family (stress, affective expression, resilience or authority) could be related, are in agreement with the results of similar studies that indicated a relationship between oppositional-defiant behaviours and style of parental discipline, socio-environmental factors and personality. ${ }^{38,39}$ However, this point needs further research.

Analysing each subscale, 'somatic complaints' stands out for having the largest mean differences. Obviously, this is directly related to the symptoms derived from allergies (asthmatic, rhinitis and atopic dermatitis). The rest of the subscales could be connected following other similar studies. ${ }^{21,40}$ Children with social, thinking or attention problems experience difficulties in expressing their feelings and emotions; this can produce anxious/depressed symptoms or aggressive behaviours. These two subscales have shown the largest differences in each factor (internalising and externalising, respectively). Secondary analyses comparing scores by group and age have revealed very interesting results that need to be explored in detail. It seems that these differences tend to decrease, as children grow older. Maybe this could be related to the maturation process of child, the acquisition of new behavioural skills, or to the lesser dependency on parents.

Third hypothesis related with dose-relation analyses showed mixed results. While there was a relation between degree of asthma (mild or moderate) and general and internalising behavioural problems, these relations disappear when compared with the number of allergies. This situation may be due to the dispersion of data, and a larger sample size may be required.

In spite of the efforts to control methodological aspects, these results must be considered within the context of some limitations. Firstly, the study's principal limitation is related to its cross-sectional design. It would be desirable to carry out a longitudinal study to increase the internal validity of results. Secondly, despite efforts to recruit subjects in different groups, we failed in the control group, in which the number of participants was less than expected in the sample size calculations. This limitation could be associated with the lack of parental involvement in a study whose results do not concern them. Thirdly, we have used a simple and ad hoc questionnaire to assess some variables (aspects related to allergy and emotional climate in the family). It would be desirable to use a more precise and well-validated tool to asses these aspects and to make comparisons with other similar studies possible. In this context, findings should be interpreted with caution, as it is not possible to ensure that these differences imply a causal phenomenon.

Lastly, in this study OR results indicated that all factors, including the overall $C B C L$ score and each individual factor, showed a higher risk of clinical behavioural problems in the sample of allergic children. In some cases, the risk of showing difficulties or problems is more than three times in the allergic group than in the

Table 4 Comparisons of child behaviour checklist (CBCL) scores by level of asthma (mild or moderate).

\begin{tabular}{lcclrr}
\hline & Mild asthma $(\mathrm{n}=\mathbf{1 5 1 )}$ & Moderate asthma $(\mathrm{n}=43)$ & P-value & Mean difference & SMD (95\% Cl) \\
\hline CBCL total, mean (SD) & $29.3(21.4)$ & $38.3(24.8)$ & 0.019 & -9.08 & $0.4[1.51$ to 16.64$]$ \\
Internalizing & $8.49(7.68)$ & $11.3(9.41)$ & 0.049 & -2.77 & $0.34[0.01$ to 5.52] \\
Externalizing & $7.26(6.05)$ & $9.12(7.47)$ & 0.09 & -1.85 & $0.29[0.32$ to 4.03]
\end{tabular}

CBCL: child behaviourchecklist; $\mathrm{Cl}$ : confidence interval; SD: standard deviation; SMD: standardized mean difference. 
control group (social problems). These findings suggest the need to investigate new strategies and interventions to treat and prevent possible mental health diseases in childhood, which is such an important stage in a person's development. ${ }^{41}$

\section{Conclusions}

These findings suggest an important association between suffering from allergies and the presence of behavioural problems in children aged 6-11 years. This relationship is stronger in internalising behaviours. Age of the children and moderate asthma appear to be protective variables. Because of the importance of children's proper mental and physical development and their transition to adulthood, clinicians should pay more attention to possible symptoms related to mental health or behavioural problems, especially in children with multiple allergic diseases or comorbidities. Early treatment and prevention programmes with children and families that could avoid or reduce the probability of manifesting these difficulties in successive stages are warranted.

\section{Acknowledgements}

We are grateful to Jennifer Benítez Navas from the Intelecto Psychological Centre, Jerez de la Frontera (Spain).

\section{Ethical disclosures}

Protection of human subjects and animals in research: This study was carried out in accordance with the Code of Ethics of the World Medical Association (Declaration of Helsinki). Right to privacy and informed consent: All participants signed the informed consent. The author for correspondence is in possession of this document.

\section{Funding}

This research did not receive any specific grant from funding agencies in the public, commercial or not-for-profit sectors.

\section{Declaration of interest}

The authors have no conflicts of interest to disclose.

\section{References}

1. Pawankar R, Canonica GW, Holgate ST, Lockey RF. White book on allergy 2011-2012 executive summary. Milwaukee, WI: World Allergy Organization; 2011.

2. Gupta RS, Springston EE, Warrier MR, Smith B, Kumar R, Pongracic J, et al. The prevalence, severity, and distribution of childhood food allergy in the United States. The prevalence of food allergy and other allergic diseases in early childhood in a population-based study: HealthNuts age 4-year follow-up. Pediatric allergy and immunology in China. Pediatrics. 2011;128:e9-17.

3. Peters RL, Koplin JJ, Gurrin LC, Dharmage SC, Wake M, Ponsonby $\mathrm{AL}$, et al. The prevalence of food allergy and other allergic diseases in early childhood in a population-based study: HealthNuts age 4-year follow-up. J Allergy Clin Immunol. 2017;140:145-53.e8. https://doi.org/10.1016/j. jaci.2017.02.019

4. Wong GWK, Li J, Bao YX, Wang JY, Leung TF, Li LL, et al. Pediatric allergy and immunology in China. Pediatr Allergy Immunol. 2018;29:127-32. https://doi.org/10.1111/pai.12819

5. O'Connell EJ. The burden of atopy and asthma in children. Allergy. 2004;59 Suppl 78:7-11. https://doi. org/10.1111/j.1398-9995.2004.00563.x

6. Loftus PA, Wise SK. Epidemiology and economic burden of asthma. Int Forum Allergy Rhinol. 2015;5 Suppl 1:S7-10. https://doi.org/10.1002/alr.21547

7. Patel N, Herbert L, Green TD. The emotional, social, and financial burden of food allergies on children and their families. Allergy Asthma Proc. 2017;38:88-91. https://doi. org/10.2500/aap.2017.38.4028

8. Fong AT, Katelaris $\mathrm{CH}$, Wainstein B. Bullying and quality of life in children and adolescents with food allergy. J Paediatr Child Health. 2017;53:630-5. https://doi.org/10.1111/jpc.13570

9. Tzeng NS, Chang HA, Chung CH, Kao YC, Chang CC, Yeh HW, et al. Increased risk of psychiatric disorders in allergic diseases: A nationwide, population-based cohort study. Front Psychiatry. 2018;9:133. https://doi.org/10.3389/fpsyt.2018.00133

10. Rhee CS, Wee JH, Ahn JC, Lee WH, Tan KL, Ahn S, et al. Prevalence, risk factors and comorbidities of allergic rhinitis in South Korea: The Fifth Korea National Health and Nutrition Examination Survey. Am J Rhinol Allergy. 2014;28:e107-14. https://doi.org/10.2500/ajra.2014.28.4040

11. Peters TE, Fritz GK. Psychological considerations of the child with asthma. Child Adolesc Psychiatr Clin N Am. 2010;19:31933, ix. https://doi.org/10.1016/j.chc.2010.01.006

12. Slim M, Rico-Villademoros F, Calandre EP. Psychiatric comorbidity in children and adults with gluten-related disorders: A narrative review. Nutrients. 2018;10. https://doi.org/10.3390/ nu10070875

13. Withers AL, Green R. Transition for adolescents and young adults with asthma. Front Pediatr. 2019;7:301. https://doi. org/10.3389/fped.2019.00301

14. Miyazaki C, Koyama M, Ota E, Swa T, Mlunde LB, Amiya RM, et al. Allergic diseases in children with attention deficit hyperactivity disorder: A systematic review and meta-analysis. BMC Psychiatry. 2017;17:120. https://doi.org/10.1186/ s12888-017-1281-7

15. McGovern CM, Arcoleo K, Melnyk B. COPE for asthma: Outcomes of a cognitive behavioral intervention for children with asthma and anxiety. Sch Psychol. 2019;34:665-76. https://doi.org/10.1037/spq0000310

16. Goodwin RD, Robinson M, Sly PD, Mckeague IW, Susser ES, Zubrick SR, et al. Severity and persistence of asthma and mental health: A birth cohort study. Psychol Med. 2013;43:1313-22. https://doi.org/10.1017/S0033291712001754

17. Tajdini M, Effatpanah M, Zaki-Dizaji M, Movahedi M, Parvaneh N, Shariat $M$, et al. Associations of behavioral disorders with asthma in Iranian children. Iran J Allergy Asthma Immunol. 2019;18:340-5. https://doi.org/10.18502/ijaai.v18i3.1127

18. Teyhan A, Galobardes B, Henderson J. Child allergic symptoms and well-being at school: Findings from ALSPAC, a UK cohort study. PLoS One. 2015;10:e0135271. https://doi.org/10.1371/ journal.pone.0135271 
19. Nanda MK, LeMasters GK, Levin L, Rothenberg ME, Assa'ad AH, Newman $\mathrm{N}$, et al. Allergic diseases and internalizing behaviors in early childhood. Pediatrics. 2016;137. https://doi. org/10.1542/peds.2015-1922

20. Chang HY, Seo JH, Kim HY, Kwon JW, Kim BJ, Kim HB, et al. Allergic diseases in preschoolers are associated with psychological and behavioural problems. Allergy Asthma Immunol Res. 2013;5:315-21. https://doi.org/10.4168/aair.2013.5.5.315

21. Urrutia-Pereira $M$, Sole $D$, Chong Neto $H J$, Acosta $V$, Cepeda AM, Alvarez-Castello M, et al. Sleep disorders in LatinAmerican children with asthma and/or allergic rhinitis and normal controls. Allergol Immunopathol (Madr). 2017;45:14551. https://doi.org/10.1016/j.aller.2016.08.014

22. Topal E, Catal F, Soylu N, Ozcan OO, Celiksoy MH, Babayigit A, et al. Psychiatric disorders and symptoms severity in preschool children with cow's milk allergy. Allergol Immunopathol (Madr). 2016;44:445-9. https://doi.org/10.1016/j.aller.2016. 03.001

23. Paller A, Jaworski JC, Simpson EL, Boguniewicz M, Russell JJ, Block JK, et al. Major comorbidities of atopic dermatitis: Beyond allergic disorders. Am J Clin Dermatol. 2018;19:82138. https://doi.org/10.1007/s40257-018-0383-4

24. Xie QW, Dai X, Tang X, Chan CHY, Chan CLW. Risk of mental disorders in children and adolescents with atopic dermatitis: A systematic review and meta-analysis. Front Psychol. 2019;10:1773. https://doi.org/10.3389/fpsyg.2019.01773

25. Lebovidge JS, Strauch H, Kalish LA, Schneider LC. Assessment of psychological distress among children and adolescents with food allergy. J Allergy Clin Immunol. 2009;124:1282-8. https:// doi.org/10.1016/j.jaci.2009.08.045

26. Brew BK, Lundholm C, Gong T, Larsson H, Almqvist C. The familial aggregation of atopic diseases and depression or anxiety in children. Clin Exp Allergy. 2018;48:703-11. https://doi. org/10.1111/cea.13127

27. Licari A, Ciprandi R, Marseglia G, Ciprandi G. Anxiety and depression in adolescents with severe asthma and in their parents: Preliminary results after 1 year of treatment. Behav Sci (Basel). 2019;9. https://doi.org/10.3390/bs9070078

28. Sicouri G, Sharpe L, Hudson JL, Dudeney J, Jaffe A, Selvadurai $\mathrm{H}$, et al. Parent-child interactions in children with asthma and anxiety. Behav Res Ther. 2017;97:242-51. https:// doi.org/10.1016/j.brat.2017.08.010

29. Tully C, Rose M, Breen S, Herrera N, Shelef DQ, Streisand R, et al. Relationship between parent mood and resilience and child health outcomes in pediatric asthma. Fam Syst Health. 2019;37:167-72. https://doi.org/10.1037/fsh0000417
30. Meštrović-Štefekov J, Novak-Bilić G, Kuna M, Pap N, LugovićMihić L. Psychological stress in patients with atopic dermatitis. Acta Dermatovenerol Croat. 2018;26:297-303.

31. Yang CJ, Liu D, Xu ZS, Shi SX, Du YJ. The pro-inflammatory cytokines, salivary cortisol and alpha-amylase are associated with generalized anxiety disorder (GAD) in patients with asthma. Neurosci Lett. 2017;656:15-21. https://doi. org/10.1016/j.neulet.2017.07.021

32. Achenbach TM, Edelbrock CS. Manual for the child behavior checklist and revised child behavior profile. T.M. Achenbach, Burlington: VT; 1983.

33. Sardinero García E, Pedreira Massa JL, Muñiz J. El cuestionario $C B C L$ de Achenbach: Adaptación española y aplicaciones clínico-epidemiológicas. Clínica y Salud. 1997;8:447-80.

34. Ogundele MO. Behavioural and emotional disorders in childhood: A brief overview for paediatricians. World J Clin Pediatr. 2018;7:9-26. https://doi.org/10.5409/wjcp.v7.i1.9

35. Cohen J. Statistical power analysis for the behavioral sciences. Cambridge, MA: Academic Press; 2013.

36. Pawankar R, Canonica GW, Holgate S, Lockey R. WAO white book on allergy: Update 2013. Milwaukee, WI: World Allergy Organization; 2013.

37. Infante M, Slattery MJ, Klein MH, Essex MJ. Association of internalizing disorders and allergies in a child and adolescent psychiatry clinical sample. J Clin Psychiatry. 2007;68:1419-25. https://doi.org/10.4088/JCP.v68n0915

38. Becht Al, Prinzie P, Deković M, van den Akker AL, Shiner RL, Rothenberg WA, et al. Child personality facets and overreactive parenting as predictors of aggression and rule-breaking trajectories from childhood to adolescence. Cross-cultural effects of parent warmth and control on aggression and rule-breaking from ages 8 to 13. Dev Psychopathol. 2016;28:399-413. https://doi.org/10.1017/S0954579415000577

39. Forster M, Grigsby T, Soto DW, Schwartz SJ, Unger JB. The role of bicultural stress and perceived context of reception in the expression of aggression and rule breaking behaviors among recent-immigrant Hispanic youth. J Interpers Violence. 2015;30:1807-27. https://doi.org/10.1177/0886260514549052

40. Garg N, Silverberg Jl. Association between childhood allergic disease, psychological comorbidity, and injury requiring medical attention. Ann Allergy Asthma Immunol. 2014;112:525-32. https://doi.org/10.1016/j.anai.2014.03.006

41. El Hennawi Del D, Ahmed MR, Farid AM. Psychological stress and its relationship with persistent allergic rhinitis. Eur Arch Otorhinolaryngol. 2016;273:899-904. https://doi.org/10.1007/ s00405-015-3641-6 